\title{
MONIQUE DAVID-MÉNARD
}

Universidad Denis Diderot - Paris VII

mdm01paris@aol.com

Traducción del francés

Melina Balcázar Moreno

\section{La institución de los cuerpos vivientes según Judith Butler The Institution of Living Bodies According to Judith Butler}

En este texto, Monique David-Ménard hace un recuento de la posición del "cuerpo viviente" dentro de la filosofía de Judith Butler, explorando relaciones en cuanto a su articulación y los mecanismos culturales que lo someten. También observa las fuentes deconstruccionistas y psicoanalíticas del trabajo de Butler, mostrando la forma en que éstas son interpretadas en un pensamiento cuyos ejes son el género, la cultura y las relaciones de poder.

PALABRAS CLAVE: cuerpo, poder, género, deconstrucción, psicoanálisis, feminismo, Judith Butler.

In this essay, Monique David-Ménard outlines the concept of the "living body" within the philosophy of Judith Butler, exploring relationships between the body itself and the cultural mechanisms that supress it. The author also observes the deconstructionist and psychoanalytic sources of Butler's work, therefore showing the way these are interpreted from perspectives of a thought whose main axes are gender, culture and relationships of power.

KEYWORDS: body, power, gender, deconstruction, psychoanalysis, feminism, Judith Butler.

La reflexión y la acción de Judith Butler en materia de género, como en muchas feministas, pretende volver inútil la referencia a la noción de naturaleza o el recurso a una noción de necesidad estructural, que impondría una repartición tajante de los géneros para que las funciones sociales se ejecuten bien. La repartición de las funciones sociales y culturales según el sexo se ha presentado con gran frecuencia como 
algo ligado a las necesidades biológicas de la procreación y a la división sexual del trabajo social. Ahora aparece como una construcción de la que no se percibe el carácter artificial, cuando se está encerrado en los presupuestos propios de una sociedad dada.

Sin embargo, lo que caracteriza en sí el pensamiento de Judith Butler es la manera en que radicaliza la deconstrucción, al hacer que se crucen y se refuercen mutuamente varias perspectivas: por una parte, en efecto, desde Gender Trouble, ha tratado de mostrar cómo la antropología estructural, debido a la fijeza de las funciones formales que designa al repartirlas según los géneros, se desprende con dificultad de un pensamiento naturalista que, no obstante, ella critica. El formalismo de la estructura no libera de la naturaleza. Por otra parte, desde los años noventa, esta lectura crítica de la antropología convergía con otro intento puntual, aunque decisivo: se trataba de interrogar los procedimientos de investigación en biología de la sexuación, que hacían parecer que ciertas hipótesis - destinadas en principio a precisar la formación de los componentes múltiples de la identidad sexual orgánica- presuponían a veces que la diferencia visible de los órganos genitales seguía siendo la norma para comprender los diversos factores de la sexuación. Lo visible impone aquí el carácter imaginario de una distinción completamente construida entre lo masculino y lo femenino, aun cuando los biólogos, al distinguir entre el sexo genético, gonádico, hormonal y ambiental quieran mostrar que esta distinción no ha sido construida, ni calcada, a partir de lo visible.

Esta influencia de lo visible, que simplificaría equivocadamente la sexuación humana, rige de igual manera, según Butler, el acercamiento filosófico del cuerpo como materia informada [informée], $\mu о \rho \eta$ desde Platón. Finalmente — last but not least—, esta naturalización indebida de la sexualidad atañe también al psicoanálisis: no solamente el psicoanálisis lacaniano en el tributo que rinde a Lévi-Strauss, sino desde el inicio, con Freud, mediante el privilegio que da al pene y al falo como modelo mismo de la erogeneidad, y que encerraría la cuestión de la diferencia de los sexos en la de la forma del órgano. Por una parte, Freud repetiría a través de esto los presupuestos no percibidos como tales de la filosofía del cuerpo vivo como forma bella, y, por otra, puesto que el papel paradigmático del pene reside en su proximidad con el dolor 
hipocondríaco, el órgano dolorosamente afectado en su excitación instituiría una proximidad contestable, aunque pasa desapercibida entre la enfermedad, lo masculino y los prestigios engañosos de lo visible cuando se trata de acercarse a lo sexual.

Cada vez que Judith Butler pone en evidencia uno de los supuestos que impera en la aprehensión de la sexuación, aparece, en contraste, una hipótesis "científica", una distinción filosófica, un acceso clínico. Lejos de ser "puros" conocimientos son actos, procedimientos que instalan cierto estatuto del cuerpo en vez de ofrecer un saber que sería puro. Por ello el método deconstructivo de Butler parece con frecuencia tan cercano a la arqueología de Michel Foucault: los saberes no están indemnes de una dimensión de institución de sus objetos que presenta una contingencia rara vez explícita, y que hace de ellos una creación de normas y no una contemplación.

Sin embargo, ¿hasta qué punto las líneas rivales de esta deconstrucción establecen que el cuerpo vivo y sexuado es en sí una construcción? Y cuando Judith Butler saca a la luz las normas activas en los saberes, ¿se aleja de la idea de naturaleza como lo hace Foucault cuando trata de la "episteme" y de los "dispositivos", o bien se trata de algo más? Mi atención se concentrará en esclarecer ciertos aspectos de estas dos cuestiones.

\section{Instituir y producir}

En primer lugar, es en la lectura crítica de Lévi-Strauss y de Lacan donde la importancia de lo que se instituye en la distinción de los géneros y de los sexos se define: al considerar el incesto como un fantasma cultural extendido - y no como un fenómeno social efectivo-, Lévi-Strauss efectúa una doble operación: por una parte, niega la realidad del incesto; por otra, muestra que la prohibición del "antiguo sueño" de incesto posee la eficacia de una instauración o de una institución de la heterosexualidad "normal" en una sociedad. La existencia de la prohibición "parece sugerir que los deseos, acciones, en efecto, prácticas sociales penetrantes de incesto son generadas precisamente en virtud de la eroti- 
zación de ese tabú. Que los deseos incestuosos son fantasmáticos de ninguna manera implica que no son también 'hechos sociales'. La pregunta es, en cambio, cómo son generados tales fantasmas y, de hecho, instituidas como una consecuencia de su prohibición?" (Butler 1990: 42).

La sucesión de los términos "produce" e "instituye" indica de entrada que Butler lee a Lévi-Strauss con la aportación de Foucault: Gender Trouble se escribe en 1990, es decir, después de la aparición de La voluntad de saber (1976). La idea foucaultiana consiste en que la prohibición como poder produce la sexualidad, es decir, la ilusión de que la verdad del sujeto se decide en el sexo, y esto a condición de que se consideren los actos sexuales como materia de prohibición y como ocasión de formación de una verdad, la del sujeto. Una producción de este tipo implica, primero, que un poder no reprima una realidad preexistente; esta tesis muestra entonces que no hay una realidad anterior a lo que produce un poder.

Butler añade: "produce, incluso instituye". ¿Qué más nos dice "instituye"? No se trata solamente, como en Foucault, de afirmar que la sexualidad es una formación discursiva entre otras, y que pueden existir socialmente otros dispositivos de subjetivación diferentes de lo que se ha llamado "sexualidad"; se trata también de comprender cómo la heterosexualidad se instaura como la sexualidad normal y la única inteligible gracias a la producción de las prohibiciones del incesto, tal como las describen la antropología estructural y el psicoanálisis: "Para Lévi-Strauss, el tabú en contra de actos incestuosos heterosexuales entre madre e hijo, así como también esa fantasía incestuosa, son instauradas como verdades universales de la cultura" (1990: 42). Lo que se instituye, se instaura, es menos ahora la sexualidad en general que la heterosexualidad.

Decir que la sexualidad es instituida significa que no tiene ningún privilegio de verdad o esencia. Y es en este punto preciso en el que Butler aprovecha al máximo a Lacan: este último, después de Joan Riviere, hace de la sexuación, tanto del lado de las mujeres como de los hombres, una "mascarada", es decir, una posición subjetiva a-ontológica. Lo femenino "es" lo que acepta fundirse en lo que lo masculino ve en ella — lo que colmaría el deseo de la madre por un hombre- e incluso si Lacan define una parte de lo femenino como un más allá del falo, 
este más allá es impensable para el hombre al estar determinado por la función fálica. La diferencia de los sexos es a-ontológica para Lacan, lo que corresponde a una crítica de toda ontología del género, aunque esto no forme aún una institución: en efecto, no hay nada antes del orden simbólico que crea, mediante la diferencia entre "ser" y "tener" el falo, lugares sexuados distintos. Pero como nada más es pensable sino este orden diferenciado, el psicoanálisis lacaniano reproduce, al igual que la antropología estructural, una naturalización de los géneros a través de una estructura que se presenta como a-temporal. Decir que la diferencia de los sexos está instituida no es solamente caracterizarla como pura posición, sino es también descubrir en la fijeza de la diferencia de las posiciones "hombre" y "mujer" una restricción de las posibilidades en materia de sexuación: "Cada esfuerzo por establecer la identidad en los términos de la disyunción binaria de 'ser' y 'tener' regresa a la inevitable 'falta' y 'pérdida' que fundamentan su construcción fantasmática y marcan la inconmensurabilidad de lo Simbólico y lo real" (44). La insistencia lacaniana en la falta de ser es entonces el índice que la crítica de la ontología se detiene en camino.

Efectivamente, Lacan muestra que, al no existir lo real de la sexualidad antes de la prohibición, lo Simbólico prohibidor funda su propia inteligibilidad sin ninguna garantía de verdad previa a su eficacia performativa, empero, niega enseguida esta performatividad debido a la fijeza de posiciones radicalmente distintas que giran en torno a la ausencia. Butler aprecia en Lacan, así como en Foucault y en Derrida, la idea de que no hay fundamento de verdad en lo que se produce; lo originario, lo fundamental, es un "efecto de ser"; el poder que instaura un orden crea su propia inteligibilidad, la cual se presenta de manera equivocada como necesaria mientras no se introduzca una ambigüedad en la distinción entre lo masculino y lo femenino. Es incluso en este punto preciso cuando Butler deja de hablar de sexuación y aborda el género. Llevar más lejos que Lacan la comedia de la ontología sexual significa efectuar realmente "una reflexión crítica sobre la ontología del género" (47). En Gender Trouble, el género es la ambigüedad de la sexuación que se vuelve pensable en lugar de ser arrojada fuera del campo de la inteligibilidad. Y es sólo así que el sexo/género se concibe como instituido. 
Esta ambigüedad es, en primer lugar, la de los procesos, antes de ser la de la distinción entre hombre y mujer: Butler toma de Joan Riviere y de Lacan la idea de que, puesto que la mujer es una mascarada, no existe una posición "mujer" sin melancolía, sin pérdida de ser, sin imposibilidad de existir y de definirse fuera de lo que se es para el otro, que no solamente impondría sus propias categorías, sino que también volvería impensable que una mujer se definiera al exterior de esta alienación. Si esta barrera hace vano el pensamiento de otras identificaciones posibles para una mujer, excluye la posibilidad de reconocer otros amores que los del falo y su más allá indeterminado. La melancolía es a la vez la experiencia de la posición sexuada de la mujer como puro correlato del falo — el hecho de que no sea nada "por ella misma"- - y el acceso a lo que la mascarada fálica revela y oculta: Lacan lo dice bien, pero sin desarrollarlo, que una parte de la feminidad de la mujer sigue padeciendo, excluida de la mascarada, aunque, simultáneamente, la mascarada oculte esta exclusión. Ahí reside su ambigüedad. Sin embargo, si la mascarada es ambigua y si no olvidamos su ambigüedad, entonces la ambigüedad misma de la distinción entre lo masculino y lo femenino puede salir a la luz: si otros objetos eróticos además del pene se colocan en lugar del falo - consolador, otra parte del cuerpo, otra actividad-, entonces la repartición tajante entre lo masculino y lo femenino se deshace, ya que la única forma de darle un contenido era organizándola alrededor de la imposibilidad de ser fálico. Todo el pensamiento de Judith Butler tiende por consiguiente a volver ambigüa, no tajante, no fija, la "diferencia de los sexos". En esto consiste, en principio, pensar el género no solamente como producido, sino como instituido. La construcción del incesto no hace sólo prohibir esto último, sino que garantiza la heterosexualidad mediante el modelo del incesto que prohíbe al volver impensables otras formas de incesto. De cierta manera, Michèle Montrelay no decía otra cosa en 1977 en L'Ombre et le nom [La sombra y el nombre], cuando hacía notar la sexualidad concéntrica de una mujer. No obstante, Butler extrae conclusiones opuestas a las de Montrelay. Para esta última, la homosexualidad de las mujeres es no prohibida por la ley que reglamenta la diferencia sexual: sería vivida y no representada en lo Simbólico, un estrato de existencia salvaje y común a la vez. Para Butler, ha sido excluida, es decir, se ha hecho de ella 
algo invivible e inconcebible, cuando de lo que se trata es de volverla vivible y pensable al hacer relativas las construcciones normativas de la heterosexualidad. ¿Cómo dar cabida a los amores cuya pérdida misma se niega en la institución de la heterosexualidad reinante?

Reservemos para otro texto la crítica de esta tesis de Butler: ¿la relación de las mujeres con las mujeres y con las madres, cuando no pasa por el falo es, desde hace veinte años, tan poco reconocida por los psicoanalistas, mujeres en particular, como lo afirma? Por otra parte, ¿la melancolía de la que trata es la misma que la que se encuentra en la clínica, tanto en las mujeres como en los hombres? Por el momento, lo que nos interesa comprender con precisión es hasta dónde se extiende el poder performativo de la institución en la construcción de los cuerpos: concierne primero el desplazamiento de una problemática de la sexuación a una de género. El género, como lo hemos visto, sería la sexuación que no se encierra en la fijeza de una repartición estable entre masculino y femenino, al ser la ambigüedad de la mascarada el puente hacia la ambigüedad de la sexuación. Aparentemente, se trata de sexuación y de género, no se trata de cuerpo, ni de cuerpo vivo. Sin embargo, desde este análisis de la institución de los géneros, Butler concentra su atención en la manera en que la melancolía informa el cuerpo vivo: los duelos no reconocidos de los amores homosexuales marcan el cuerpo: "La máscara es tomada a través del proceso de incorporación, que es una manera de inscribir y después de ponerse una identificación melancólica en y sobre el cuerpo; en efecto, es la significación del cuerpo en el molde del Otro que ha sido rechazado" (Butler 1990: 50). Enmascararse es dar forma a su cuerpo. Y el cuerpo sexuado, en sus movimientos, gestos y expresiones no es nada más que la sedimentación de las identificaciones aceptadas o rechazadas.

La institución del cuerpo sexuado y de la forma viva

Desde Gender Trouble, Butler trata de hacer pensable y vivible una ambigüedad de la sexuación que no se contenta con el concepto confuso de bisexualidad y que tampoco sueña con una edad de oro indemne de 
separación. ${ }^{1}$ Hay que sostener a la vez que toda repartición de los géneros está instituida, que no hay edad de oro anterior a las leyes y que, no obstante, varios tipos de normas de género son concebibles: hablar de melancolía del género implica pensar también la posibilidad de otras leyes que determinen la sexuación que instaura la heterosexualidad exclusiva: "Si la subversión es posible, será una subversión que emana de los términos de la ley" (Butler 1990: 93).

No se puede persistir en la inexistencia de una esencia en materia de género y presuponer que habría, en el transexualismo por ejemplo, una experiencia anterior a toda división. Butler localiza, incluso en Foucault, una tendencia a idealizar indebidamente un paraíso anterior a la diferencia, cuando trabaja en el caso de Herculine Barbin. Sin embargo, se puede mostrar cómo toda institución del reparto entre los géneros excluye otras posibilidades que las que hace inteligibles y vivibles. A través de este medio, la institución produce la sexuación como juego de máscaras.

En Gender Trouble, el carácter instituido del cuerpo se localiza en el privilegio de lo visible del cuerpo como forma: definir el cuerpo como forma presupone que la materialidad del cuerpo es fija y la fijeza de la diferencia entre mujer y hombre no es más que uno de los aspectos de este presupuesto que reina tanto en biología como en psicoanálisis. De ahí la importancia del breve texto que introduce la problemática de los "Actos corporales subversivos" (Subversive Bodily Acts) y que Butler llama con humor "Postdata conclusiva no científica" (Concluding Unscientific Postscript) (1990: 106). El carácter performativo del reparto de los géneros que tiende a ignorar la ambigüedad de sus relaciones se manifiesta incluso en el trabajo de los científicos: mientras que la biología de la sexuación tiende a pluralizar los factores determinantes del sexo -componentes genéticos, gonádicos, hormonales, ambientales-, con frecuencia ocurre que los científicos busquen un criterio unívoco de la distinción entre mujer y hombre, un factor genético que sería responsable también de la diferencia clara de las formas masculina y femenina. Al hacer esto, presuponen equivocadamente la verdad de lo que están,

${ }^{1}$ Según Judith Butler, incluso Foucault, en su comentario sobre Herculine Barbin, sueña con una edad de oro anterior a toda distinción de los sexos. 
empero, interrogando, tan difícil les resulta aceptar que existe ambigüedad, no univocidad en los cuerpos sexuados.

Cuando el sexo genético (XX o XY) y el sexo visible (pene o no pene) no coinciden, ciertos investigadores, como el Dr. Page, intentarán poner en evidencia un desplazamiento del factor diferenciador para no renunciar al ideal de una unidad posible de los diversos factores que construyen el cuerpo sexuado: "Page y sus colegas plantearon la siguiente hipótesis: Tiene que haber algún tramo de ADN, que no puede ser visto bajo las condiciones microscópicas usuales, que determina el sexo masculino, y este tramo de ADN tuvo que haber sido movido de alguna manera del cromosoma Y, su lugar habitual, a otro cromosoma, en donde uno no se esperaría encontrarlo" (1990: 107). Decir que el cuerpo biológico sexuado está instituido supone aquí mostrar cómo les cuesta soportar a las hipótesis científicas la ambigüedad en la composición de los factores de la sexuación.

No obstante, esta crítica epistemológica va aunada a una tesis filosófica acerca del cuerpo como forma viva que se despliega después con coherencia en Bodies That Matter (1993). Cada vez que se considera el cuerpo como un visible dado, forma estable o dualidad establecida del masculino y del femenino que se guía por la visión de los órganos genitales, de hecho se instituye el cuerpo mediante una operación normativa que se ignora a sí misma.

Esta confianza indebida toma varias formas: primero, como acabamos de verlo, puede infiltrarse en las hipótesis biológicas que buscan un "conmutador decisivo" de la diferenciación sexual. Sin embargo, Bodies That Matter muestra que la filosofía platónica del espacio e incluso las tesis aristotélicas sobre la forma del cuerpo capaz de unificarse en un alma son tributarias de la performatividad de los géneros que no se establecen distinguiendo el sexo pensable, masculino, de la materia informe e indeterminada, femenina.

La afirmación de que el cuerpo no es un dato material sino el resultado de un proceso de materialización cobra su sentido, en principio, en los debates de las teóricas del feminismo norteamericano de los años noventa: el género no es una determinación social y simbólica que vendría a calificar un dato previo "puramente físico". Es este dato previo, y con ello la idea biológica de forma corporal independiente de lo que 
la sociedad añadiría en ella, lo que hay que poner en cuestión. Para ello, hay que concebir la formación de los cuerpos como el resultado de imposiciones normativas que se ejercen en el tiempo, de manera repetitiva. Así pues, se ha pensado demasiado el organismo como una realidad espacial, y no lo suficiente como la materialización continua de imposiciones repetitivas que termina por moldear los cuerpos gracias a la manera en que los individuos incorporan las imposiciones. Los llamados transexuales, travestis, homosexuales, justamente no han materializado estas imposiciones como la mayoría. Las imposiciones tomaron cuerpo de otro modo en ellos. Y el régimen dominante de la heterosexualidad resulta perturbado por ellos, sobre todo cuando gays y lesbianas se manifiestan públicamente, haciendo visible lo que debe permanecer irrepresentable.

Butler se refiere a Derrida ${ }^{2}$ cuando insiste en la temporalidad de las imposiciones que materializan los cuerpos. Aunque uno podría referirse también al Bergson de La evolución creadora, o bien a los trabajos actuales de ciertos neurobiólogos para confirmar que el organismo en sí, en todas sus funciones, es todo salvo una forma fija. Butler privilegia el cuerpo sexuado y la incorporación temporal de las normas que lo modelan.

\section{¿El cuerpo erógeno es un efecto de discurso?}

Esta insistencia en la conexión entre la performatividad del género y el privilegio que se otorga sin reflexionar a la forma del cuerpo vale también para la construcción del cuerpo en el psicoanálisis desde Freud. Tal es la aportación específica de Bodies That Matter: no basta con decir que los poderes sociales y simbólicos imponen la diferenciación tajante de los sexos para comprender cómo la materialidad misma de los cuerpos se instituye, no sólo a través de los discursos sino también de las imposiciones normativas que se despliegan en el tiempo. Este estudio sobre la materialidad de los cuerpos se distingue a la vez de Foucault, quien reducía el cuerpo a comportamientos formateados por las dis-

2 J. Derrida. Donner le temps, 1. La Fausse monnaie. Paris: Galilée, 1991. 
ciplinas, así como de las investigaciones feministas que consideran el género como una determinación social que sobredeterminaría un dato corporal puramente orgánico.

Hablar de materialización, más que de materia dada de los cuerpos, es hacer de los contornos del cuerpo el resultado de un proceso de delimitación. La lectura crítica de Freud es un ejemplo del acceso al cuerpo como materialidad: ¿cómo construyó Freud la materialidad de los cuerpos? Mediante la confluencia entre la atención hipocondríaca a los dolores de los órganos y el privilegio del narcisismo fálico: más precisamente, Butler sigue, en los textos freudianos desde Introducción al narcisismo (1914), la aclaración del "cuerpo erógeno": la idea de una investidura erótica del cuerpo propio, que acapara la vida sexual y que él llama narcisismo, la cita primero en el registro de la oralidad: en los dolores dentales, "el universo se reduce al rincón estrecho de una muela" (1993: 58). Pero este abismo oral, ligado a la experiencia del dolor corporal que acapara la investidura erótica se extiende después a todo el dolor a través de la comparación con la hipocondría: inventarse enfermedades a partir de una presencia del cuerpo en el que habitan dolores difusos y cambiantes es una forma de narcisismo. Esta preocupación de sí es lo que Freud compara al erotismo fálico: "conocemos" un órgano dolorosamente afectado, aunque no está enfermo, se trata del pene en erección. Y por un desplazamiento de la erotización del dolor hacia la experiencia de la tumescencia del pene, Freud, más adelante, en "El Yo y el Ello", llega a escribir - algo que Butler destaca — que tal vez el dolor interviene de manera general en la erogeneidad de un cuerpo. Butler borra el matiz freudiano que introduce el "tal vez" y hace de esta línea unificada por el narcisismo de los dolores oral, orgánico, fálico, el modelo mismo del cuerpo erógeno en Freud. Y — last but not least - esto se refuerza ya que Freud caracteriza la instancia llamada psíquica del Yo como solidaria de la influencia de lo visual y de la forma que se impone con el tema de la erección: el Yo no es solamente, escribe Freud, una "entidad de superficie", sino la proyección de una superficie, como en la triste búsqueda de Narciso que murió por identificarse con los contornos de su cuerpo. Lacan habrá dado una importancia más grande aún a esta conjunción de lo escópico con lo fálico al hablar del estadio del espejo y del Imaginario. 
Por otra parte, las interminables discusiones sobre las relaciones del pene y del falo refuerzan este desplazamiento metonímico del pensamiento que no define el cuerpo erógeno pero que lo pone en escena mediante la retórica del texto. El falo no coincide más que por azar con el órgano pene, ya que el falo es el significante de la ausencia y que su adecuación con la experiencia de la destumescencia y de la tumescencia del pene es a la vez indispensable aunque se la presenta siempre como secundaria.

Una de las maneras en las que el psicoanálisis ejerce una acción normativa en la materialización de los cuerpos consiste en hacer de estos deslizamientos metonímicos sucesivos — dolor oral, dolor erógeno, turgencia del pene, dolor en la erogeneidad en general, interés en la forma de los órganos, Yo entidad de superficie, prevalencia de lo Imaginarioel modelo mismo del cuerpo erógeno. Para atenerse al proceso, habría que decir que la "erogenización" del cuerpo fija su forma sexuada. Butler señala la falta de rigor en esta definición del cuerpo erógeno: “¿Se trata de una consciencia que inyecta dolor en el objeto y mediante ello le da contornos, como ocurre con la hipocondría? O bien, ¿es un dolor causado por la enfermedad orgánica que respectivamente una consciencia atenta a este dolor ha grabado?” (1993: 59). Y, con respecto de la sexualidad fálica que terminaría por representar toda sexualidad, señala de igual forma una inconsecuencia, una falta de lógica: ¿las zonas erógenas son substitutos de los órganos genitales en los síntomas de diversas neurosis o bien la erogeneidad del falo es ya el efecto textual de deslizamientos practicados en los textos freudianos que adaptan la ficción de los desplazamientos de las zonas erógenas? (60).

No obstante, Butler no se detiene primero a denunciar lo que le parecen ser inconsecuencias, lo que le importa es más positivo: si el cuerpo erógeno es una realidad imaginaria que la retórica de los textos ha instituido, ¿cuáles son las otras representaciones del cuerpo que esta retórica excluye? A fin de mostrar que toda concepción del cuerpo sexuado excluye, al mismo tiempo que vuelve representables, ciertos cuerpos, no está de más identificar sus inconsecuencias lógicas. El único límite a esta deconstrucción radical del cuerpo erógeno es que Butler no quiere ir hasta decir que "el cuerpo sexuado" es un puro efecto de lenguaje, ya que, nos dice, existe también en el lenguaje mismo una materialidad de los signos que su función significante no absorbe. Su perspectiva no es 
idealista, puesto que en lo que parece ser una ocasión para el idealismo - reducir el cuerpo a lo que la retórica del cuerpo erógeno instituye de él- encuentra materialidad en el lenguaje.

La segunda razón que evita el escollo del idealismo es que al renunciar a la sola lectura de los textos psicoanalíticos, Butler evalúa el vacío del significante "mujer" confrontándolo con la concepción del sentido propio y del sentido figurado en Saul Kripke y la concepción del performativo en Slavoj Zizek, con lo que los desea establecer. Descubre, en la imposibilidad de fijar el significante "mujer", una determinación política: "mujer" es menos un significante vacío o eternamente por llegar, debido a razones estructurales y simbólicas, como lo afirman Lacan o Zizek, que un significante cuyos correlatos sociales son excluidos en el discurso dominante. ${ }^{3}$ De ahí el interés que representa estar atenta a los desplazamientos significantes de los términos cuyo referente es indesignable, en lo que Butler destaca en lograr: la propiedad performativa de ciertos sintagmas se encuentra directamente ligada a una política del género: "Que la categoría [mujer] no pueda ser descriptiva nunca es la condición misma para su eficacia política" (Butler 1993: 221). Esto vuelve interesante, por ejemplo, el significante "queer", ya que en primera instancia es un insulto o una marca de vergüenza impuesta por los demás a una forma de vida sexual que está excluida de representación social. Esto establece un puente con lo que será el propósito de Giving an Account of Oneself: la referencia de un "Yo" es ante todo una respuesta a lo que nos llega de los otros; todo el problema consiste en saber si es sólo a partir de la vergüenza o de la culpabilidad como un "Yo" toma la palabra y un cuerpo adquiere forma.

Performativo y normativo en Foucault y Butler

Permanezcamos sin embargo todavía en ese momento que representa Bodies That Matter: si no hay ser ni esencia de lo femenino y la esencia

\footnotetext{
3 "The constitutive instability of the term, its incapacity ever fully to describe what it names, is produced precisely by what is excluded in order for the determination to take place" (Butler 1993: 218).
} 
supuesta de lo masculino es producto de esta determinación excluida del significante "mujer", debe quedar vacío para que lo masculino fálico tenga un contenido, ¿cuál es exactamente la relación entre la institución del cuerpo erógeno y sexuado y el poder lingüístico de lo performativo?

Al final de su libro, Butler retoma una definición clásica de performativo: "un término es performativo, no simplemente refiere, sino que actúa de tal modo para constituir eso mismo que enuncia" (1993: 217). Sin embargo, me parece que hay más de un uso butleriano del performativo que el de la clásica definición de Austin. Por ejemplo, cuando la autora describe la performatividad de la Ley simbólica en Lacan, observa que la Ley se produce a sí misma y produce su propia inteligibilidad, de tal manera que no hay nada "antes" de ella, y que lo presimbólico es una ilusión retrospectiva. Ahora bien, en la noción lingüística de performatividad no hay un factor de origen y no hay la misma superposición de la producción de una realidad y de su propia inteligibilidad. La noción de performativo en Butler es la de un poder instituyente, que instituye incluso los cuerpos, porque un mismo acto produce su existencia y lo que la hace pensable. Y esto tal vez porque lo vivible y representable son separados por una exclusión fundamental de lo que permanecerá fuera del campo de las formas aceptables y entonces vivibles. ¿No es acaso debido a que se piensa la producción a partir de lo que excluye que la existencia y su propia inteligibilidad se efectúan en conjunto? Efectivamente, en lingüística, lo performativo tiene como sentido "lo que efectúa", pero esto no implica que dicho acto de lenguaje excluya otros aspectos de la significación para que se produzca, y, por ende, el significado, consignado por lo performativo, no hace nulo un supuesto significado que se pretendería indemne de todo acto. Mientras que, para Butler, el hecho de que la materialidad de los cuerpos es inasible como un hecho de experiencia se debe a que su propia materialización es resultado de imposiciones sociales e inconscientes y se alimenta originariamente de exclusión.

Cuando Butler enuncia que la "Ley simbólica" es un performativo, el acto es doble: por una parte, el establecimiento de la Ley no tiene otro sentido que el que efectúa, a saber, el de repartir los sexos y la filiación según un modelo llamado "prohibición del incesto". Pero, por otra parte, al hacer esto, lo performativo excluye de la existencia y de la 
representación otras formas de incesto concebibles y hace que parezca que existencia y pensamiento de la existencia coinciden. Sin embargo, es primero porque se afirma que coinciden en lo que se excluye como se llega a pensar que coinciden también en lo que se produce.

Hay aquí un hegelianismo residual, aunque decisivo, en el pensamiento de Butler. Primero, a partir del no ser, que Hegel, en la Ciencia de la lógica (1812), se da la ocasión de pasar del pensamiento al ser: porque, escribe, persiste una diferencia entre no pensar en absoluto y pensar un no-ser indeterminable que el no ser se transforma en algo del ser que Hegel denomina Dasein, es decir, justamente, existencia o serahí. El performativo de este acto de pensamiento al que el filósofo nos invita no tiene el poder instituyente de un ser-ahí, sino porque el acto consiste, por el puro pensamiento, en extraer una especie de ser del no ser. No obstante, tal paso del pensamiento a un ser-ahí no puede efectuarse cuando la categoría que se explicita es positiva. Hegel era ampliamente consciente de lo que efectuaba en ese momento, ya que había afirmado, en 1806, que la negatividad es la estancia mágica que convierte lo negativo en ser, y asumía el idealismo de su posición al decir que todo pensamiento que se apodera de su propia verdad es idealista.

De igual forma, ¿no es porque se piensa la institución de la Ley simbólica a partir de lo que excluye y que no tiene existencia al estar separado de dicha Ley, la razón por la que Butler puede decir que, en un performativo, una existencia y su propia inteligibilidad coinciden? ¿Y no es por está razón que lo performativo y lo normativo como poder se superponen en su pensamiento?

Como contraejemplo, examinemos lo que Foucault describe, desde sus primeros libros, como institución o poder: Butler comparte con él la idea de que la contingencia de ciertas formaciones discursivas va de par con el hecho de que éstas no tienen esencia. Por ejemplo, el "Gran encierro" no es otra cosa que el conjunto instituido por el acercamiento a la vez institucional y conceptual de dominios de la realidad histórica hasta entonces distintos: el modo de exclusión de la locura se produce al principio de la Edad Moderna y de las sociedades burguesas, mediante actos convergentes en dos esferas distintas de la realidad social. Por una parte, una medida administrativa encierra en el mismo espacio a los sin trabajo, a los libertinos y a los locos en las antiguas leproserías que 
se volvieron inútiles desde que la lepra se eliminó en Europa. Por otra parte, Descartes excluye la posibilidad de que esté loco cuando produce el acto de "dudo, pienso, soy, esta proposición es necesariamente cierta cada vez que la pronuncio o que la concibo en mi mente". Lo que se instituye aquí, dice Foucault, es un mismo modo de exclusión de la locura: pierde su especificidad social, ya que se la percibe en adelante con el libertinaje y el desempleo; por otra parte, se vuelve radicalmente diferente del ejercicio del pensamiento como capacidad de producir verdad, es decir, como claro y distinto. Hay una performatividad del "Gran encierro" en la que la locura no tiene esencia, no es más que lo que las sociedades hacen de ella a través de la manera en que la excluyen de diversas maneras. $Y$ hay también una especie de performatividad en la convergencia de una medida administrativa y de una meditación filosófica, ya que el lugar de los locos sufre ahí una reconfiguración equivalente. Sin embargo, Foucault nunca dirá que la creación de los hospitales generales y la escritura de las Meditaciones metafísicas son el mismo hecho, puesto que un mismo modo de exclusión puede identificarse en ellos conceptualmente. El pensamiento no produce el ser, aunque sí es capaz de disolver la ilusión de una esencialidad de fenómenos que relaciona a sus condiciones contingentes, si bien inteligibles, de producción. En una institución, en sentido foucaultiano, lo real se describe como producto sin que se produzca a partir de su esencia.

Otro ejemplo se encuentra en Vigilar y castigar, en donde Foucault muestra que en el siglo xIx, en el espacio de la prisión, un acercamiento se produjo performativamente entre la psiquiatría y las prácticas judiciales, ya que, por razones heterogéneas, los jueces y los psiquiatras hacen resaltar a los "individuos". Los psiquiatras se interesaban en lo que llamaron "individuo" porque intentaban percibir las múltiples relaciones de lo patológico y lo normal. Por su parte, los jueces que tenían que decidir la suerte de los prisioneros encerrados en un espacio carcelario después de un juicio tuvieron que matizar las decisiones judiciales a causa de la prolongada duración del encierro de los prisioneros: la diferencia de sus conductas en prisión se volvió importante porque convenía organizar la duración de las encarcelaciones. A través de esto, se volvieron sensibles a los "individuos", lo que finalmente llevó a la creación de los “jueces de aplicación de penas”. 
En ambos casos, psiquiatría y sistema judicial produjeron al individuo como realidad y categoría. Pero esto no significa en absoluto que el individuo de los psiquiatras sea el mismo que el de los jueces del régimen carcelario. Lo que acercó los dos movimientos fue la necesidad, para la psiquiatría naciente que deseaba ser aceptada por la sociedad, de mostrar que su saber podía ser útil. Por su parte, los jueces recurrieron a los psiquiatras para ajustar la aplicación de las penas. El que se haya puesto en primer plano a los individuos es el resultado performativo, es decir, sin determinación de esencia, de este doble movimiento. Sin embargo, no podría decirse que la denominación "individuo" crea su propio contenido material al mismo tiempo que su significación por el acto mismo de su producción: el pensamiento que describe su proceso no efectúa la producción. Y esto se encuentra ligado al hecho de que Foucault describe "positividades".

Me parece que en la concepción de la performatividad de la Ley simbólica y de la institución de las formas vivas y de los cuerpos sexuados, Butler sitúa el análisis crítico en el mismo plano que la performatividad de los procesos que aborda. Por eso, completa el "producir" foucaultiano mediante un "instituir" butleriano, en el texto que cité al principio de este estudio.

\section{Epílogo}

A partir de estas observaciones, habría que regresar a algunos puntos de discusión, en particular, a su lectura de Freud, en la que Butler descuida lo siguiente: un año después de "Introducción al narcisismo", Freud redacta su texto sobre "Las pulsiones y destinos de pulsión". Ahora bien, no trata ahí del modelo fálico de la sexualidad ni de la hipocondría, ni del abismo doloroso de la oralidad que daría lugar al cuerpo erógeno. Cuando vuelve a este tema en "El Yo y el Ello", años más tarde, es de pasada y con una reserva: tal vez, el dolor es un factor en la erogeneidad. Así pues, habría que retomar esta discusión.

Por otro lado, concuerdo con Butler en que el lenguaje freudiano sobre el psiquismo y lo orgánico es confuso. Pero ¿no es acaso porque estos términos, que Freud encontraba en el vocabulario de finales 
del siglo XIX, son incapaces de concebir lo pulsional? He señalado de igual manera que convendría confrontar lo que Butler denomina como la melancolía del género con las situaciones que nos hacen hablar de melancolía en la clínica. Y que quizás ciertas y ciertos psicoanalistas, en el periodo mismo en que Butler practica sus lecturas críticas de las teorías analíticas constituidas, producían otras, más atentas a los destinos pulsionales insuficientemente legibles en los modelos reinantes. Sin embargo, esto será en otra ocasión.

\section{BIBLIOGRAFÍA}

Butler, Judith. Gender Trouble. Feminism and the Subversion of Identity. New York: Routledge, 1990.

Butler, Judith. Bodies That Matter: On the Discursive Limits of "Sex". New York: Routledge, 1993.

Derrida, Jacques. Donner le temps, 1. La Fausse monnaie. Paris: Galilée, 1991.

\section{MONIQUe DAVID-MÉNARD}

Monique David-Ménard es doctora en psicopatología clínica y psicoanálisis por la Université Paris VII. Desde 2005 es directora del Centre d'études du vivant en la Université Paris VII-Denis Diderot, donde es investigadora emérita, y miembro de la Sociedad de Psicoanálisis Freudiano. Algunas de sus obras son: Les Constructions de l'universel (PUF, 2009); Autour de Pierre Fédida (PUF, 2007); Deleuze et la psychanalyse (PUF, 2005); La Folie dans la raison pure (Vrin, 1990); L'Hystérique entre Freud y Lacan (Éditions universitaires: 1983). Su trabajo indaga sobre las conexiones del psicoanálisis con el cuerpo, la sexualidad y el lenguaje, desde una perspectiva freudiana. 